\title{
A Study on Students' Integrative Motivation for College English Learning in Chinese Universities
}

\author{
Dongmei Wang \\ Department of Freshmen Education, Yangtze University, Jingzhou, Hubei, China \\ 244676463@qq.com
}

\begin{abstract}
In foreign language learning and teaching, learner's motivation is a focus and discussed by many researchers from various perspectives. College students' English learning motivation is one of those many research subjects. It has great influence on the frequency of using learning strategies, the acceptance of second language input, the interaction with the native speakers, the setting of goals and the learner's determination of learning a foreign language. Based on Gardner's motivation dichotomy, this thesis adopts quantitative approach to study the integrative motivation of Chinese college students. This study is undertaken for the following purposes: firstly, to identify students' integrative motivation, and then to provide some useful suggestions on how to enhance students' integrative motivation.
\end{abstract}

Index Terms - English learning, integrative motivation, enhancing methods

\section{Introduction}

\section{A. Definition of Motivation}

Motivation is a complex individual variable in SLA. Its multi-faceted nature attracts scholars to continue their research. However, there is no absolute and unanimously accepted concept of motivation, let alone a thorough description of its nature in just one framework.

Gardner's definition of motivation is best known and frequently quoted. He defines motivation to learn a L2 (Gardner, 1985: 1) as "the extent to which the individual works or strives to learn the language because of a desire to do so and the satisfaction experienced in this activity". Gardner (Tremblay \& Gardner, 1995) explains that this definition includes three components: (a) effort expended to achieve a goal, (b) a desire, to learn the language, (c) satisfaction with the task of learning the language.

\section{B. Integrative Motivation}

There exist two major classifications of motivation: integrative/instrumental motivation and intrinsic/extrinsic motivation. According to Gardner, an integrative orientation is one of the factors that contribute to integrative motivation, and instrumental orientation contributes to instrumental motivation. The integrative motivation effects whether the individual learners identify with the target culture and people in some sense, or reject them. Learners with strong integrative motivation admire the target culture, and are quite eager to learn its history, society, and are full of curiosity about the structure and expression of the target language. So the process of SLA, for them, is just a way of pursuing fresh and new things, full of pleasure. To identify with the target culture, learners may read its literature, listen to its music; look for opportunities to practice the language, and so on. In a word, learners try every means spontaneously to integrate with the language.

In contrast to integrative motivation, instrumental motivation is described as that individual learners want to acquire a new language as a means for attaining instrumental goals. The learning of the L2 is out of an ulterior motive unrelated to its native speakers, that is, for some functional reasons, such as meeting the requirements for university entrance, passing different kinds of language tests, applying for a job, requesting higher pay based on language ability, reading technical materials or achieving higher social status. Learners with instrumental motivation may also do as those with integrative motivation do, but they do so because of necessity, not satisfaction.

In his research, Gardner (1985) finds a high correlation between integrative motivation and learning achievement of the L2, thus concluding that integrative motivation may be an important requirement for successful language learning.

\section{Research Design and Methodology}

In this study, we want to find out the student' integrative motivation for College English learning in Chinese universities, and then propose practical suggestions to enhance their motivation.

It is hoped that it may advance the current knowledge. In addition, we want to have a general idea about how to take advantage of the valuable experiences in College English Learning and to explore possible solutions to the problems.

The subjects in this research represent the diversity, which is present in Yangtze University. As English classes are given in grades 1 and students spend most of their freshman year studying English in Yangtze University, we chose 121 students from grade 1 of different majors. None of them is majoring in English language or English literature, but like almost all first-year university students, they take English classes as a compulsory subject, using textbooks selected without reference to their major.

All the subjects were very helpful and serious to answering the questions.

The instrument used in this study is questionnaire, which can express and verify the research questions entirely. The primary purpose, to identify students' integrative motivation for College English Learning in Chinese universities, requires the investigation of a relatively large number of students' perceptions of English. For this purpose, the questionnaire is the most appropriate method - primarily for logistical reasons, due to the large number of students, but also because using a 
questionnaire allows shy students largely unused to voicing their own opinions to respond without embarrassment and in anonymity. The date was analyzed by EXCEL.

In the present questionnaire, students are presented with 5 statements and asked to rate (in accordance with five point Likert scales) their varying degrees of:

Agreement: strongly agree - 5, agree - 4, neutral - 3, disagree - 2, strongly, disagree - 1. The questionnaire concerning the Chinese universities was conducted on March 18, 2014 in Yangtze Universities.

The questionnaire was administered during class time .The researcher distributed the questionnaires to all the subjects and made specific explanation about each item. All the participants are free to ask questions concerning the items on the questionnaire. The subjects were given about 20 minutes to finish the questionnaire. Before handing out the questionnaires, the teachers were very helpful and responsible by giving the students some instructions and explaining the importance of this study. All the questionnaires were collected within the given time. When the students were working on the questionnaire, the teacher helped with one or two statements when they didn't understand. On the whole, there were no big problems of understanding.

\section{Students' Integrative Motivation}

Table 1. Integrative Motivations of Chinese College Students

\begin{tabular}{|c|c|c|c|c|c|c|}
\hline Question & mean & $5(\%)$ & $4(\%)$ & $3(\%)$ & $2(\%)$ & $1(\%)$ \\
\hline Q1 & 3.39 & 7.55 & 41.52 & 37.73 & 8.49 & 4.72 \\
\hline Q2 & 3.2 & 4.71 & 30.19 & 47.18 & 16.04 & $1.89 \%$ \\
\hline Q3 & 1.98 & $0.00 \%$ & 5.67 & 17.91 & 45.28 & 31.13 \\
\hline Q4 & 3.29 & 11.32 & 34.91 & 28.30 & 22.63 & 2.84 \\
\hline Q5 & 2.14 & 0.00 & 11.33 & 19.81 & 40.56 & 28.30 \\
\hline
\end{tabular}

The suggestion students most agreed with was that they wanted to meet and converse with more and varied people in the world. The total percentage of "strongly agree" and "agree" comes up to $48.07 \%$. That is to say, nearly half of the students thought that we would like to communicate with English-speakers.

Another suggestion that most of students agreed with was that they learn English to enjoy foreign culture - for example, music, sports, and movies. The total percentage of "strongly agree" and "agree" comes up to $46.2 \%$. Any number of reasons can be postulated for this - students with overseas experience might simply have other more pressing motivations (understanding people rather than enjoying culture, for example). Also, for students without experience overseas, foreign culture in the form of foreign movies and music (etc.) is almost certainly their main source of contact with English outside of the classroom/examinations system.

Next were the suggestions that students learn English to enjoy foreign culture, and better understand English-speaking countries. Chinese society has been greatly influenced by the western culture, especially since the opening up. Students can get easy access to foreign culture----for example, music, NBA, and American movies. Some of them even have become part of their every life.

Ranking lowest is the suggestion that students learn English in order to behave in similar ways to English-speaking people. No one strongly agreed with it. The percentage of "agree" only accounted for $5.67 \%$. The concept of "integrative motivation" (aimed towards integration or assimilation into the target society) has very little application in China, where there is little target language society immediately present.

The relatively low mean response was the statement that "I will be out of a circle of my friends if I do not study English." (mean response 2.14). Many Chinese students don't think they would be left out or left behind by a group of their friends if they did not study English. College English learning is a compulsory course, and it is something they study in class, but not a language they will use in their daily life to some extend.

Generally speaking, the mean responses by Chinese university students are not very high in general, with the highest 3.29 and the lowest 1.98. Especially for Question 3, the mean responses by Chinese university students is only 1.98.That shows almost all students hold negative opinion towards the statement that they learn English because they want to behave in ways similar to English-speaking people.

About $7 \%$ Chinese students strongly agree that they learn English because they want to meet and converse with more and varied people in the world, however about $42 \%$ strongly agree that they learn English because they want to meet and converse with more and varied people in the world. The same tendency appears in their responses to Questions 2 and 4. The root for it may be the fact that Chinese English learners have limited English resources to refer to, among which the most important one is the native environment. They do not have many opportunities to talk with English people, to understand and appreciate English culture, which make it very difficult to experience the pleasure that English could bring to them.

About 31\% Chinese students strongly disagree that they learn English because they want to behave in ways similar to English-speaking people. About $28 \%$ Chinese students strongly disagree that they will be out of a circle of their friends if they do not study English. In Chinese Universities, although many colleges and universities have foreign teachers, it is impossible for these foreigners to assign enough time to communicate with every student, taking the large number of students into consideration. Under such situation, it is more difficult to foster Chinese students' integrative motivation.

\section{Suggestions \& Conclusion}

\section{A. Creating a Pleasant and Supportive Learning Atmosphere}

A quite tense learning climate can undermine learning and denominate learners. On the other hand, learner motivation will reach its peak in a safe learning climate in which students can express their opinions freely and feel that they do not run the risk of being ridiculed. To be fully motivated, students need both ample opportunities to learn and steady encouragement and support of their learning efforts as well. 


\section{B. Providing Activities for Communication}

Another quite effective way to cultivate language learners' motivation is to encourage them to have more communicative activities, especially those activities associated with native speakers. Because some researchers believe that a large part of motivation lies in social activities, which emphasizes the great importance of communicative desirability in learners. In fact, the ability to get meaning across and the pleasure in communication are good ways to increase the enjoyment of participating in learning tasks.

\section{Choosing Interesting Teaching Materials}

As far as learners are concerned, the materials they hear or read work as input in learning process and affect their learning motivation.

Vivid materials about English speakers' daily life or stories are attractive to learners, some of whom show great passion in learning a language because of his or her beloved movies, books and so on. In the class, it is necessary for teachers to introduce some reading or visual materials associated with texts, such as history events, holidays, delicious food, sports and entertainment in the countries. Culture teaching is an effective way in language teaching. In communication, cultural mistakes are less tolerated. More knowledge and information from language teachers will expose learners to the culture. Learners' interest in the culture of native English speakers will initiate their integrative motivation to English learning.

\section{Adopting Modern Facilities}

One practical way to enhance opportunities for students to interact with English-speakers is to facilitate that interaction via the Internet. For example, learners could participate in joint projects via the Internet with English-speaking students from other countries for a variety of learning, culture and communicative purposes. Computing facilities and Internet connection speeds now commonly available on campus allow not only email communication but also easy video conferencing (the necessary software is built into recent versions of Microsoft Windows(TM) and is, with an internet connection, otherwise free to use). Especially as students are strongly motivated to learn English as an international language, such students need not be face -to -face with native speakers of English.

In summary, there are a number of ways for teachers to enhance students' integrative motivation in English learning. Strategies as creating predictable learning environment and organizing individualized language learning activities are all aimed to activate learners' interest in language learning. It should also be noted that all these motivational strategies could not exist independently. The influences of the teachers are of prime importance for enhancement of students' integrative motivation. Teachers need manipulate these strategies flexibly according to different situations and different subjects when applying them in real English classrooms. English teachers should always keep an eye on their students' English learning motivation and give appropriate guidance in time to prevent students' learning motivation from moving in a downward direction.

\section{References}

[1] Jeremy Harmer. How to Teach English, Addison Wesley Longman 1998

[2] Keith Johnson. An Introduction to Foreign Language Learning and Teaching, Pearson Education Limited 2001

[3] Ur, P. A Course in Language Teaching: Practice and Theory, Foreign Language Teaching and Research Press.2000

[4] Gardner, R. C. \& Lambert, E. W. Attitude and Motivation in Second-Language Learning. Massachusetts: Newbury house Publisher.1972

[5] Richards, J. Approaches and Methods in Language Teaching, Foreign Language Teaching and Research Press.2000

[6] Cohen, A. D. Strategies in Learning and Using a Second Language, Foreign Language Teaching and Research Press.2000

\section{Appendix - Questionnaire on Students' English Learning Motivation}

YOUR CURRENT MOTIVATION FOR LEARNING ENGLISH

Please indicate the extent to which you agree or disagree with the following statements.

$$
\text { Strongly agree---5 Agree---4 Neutral---3 }
$$

Disagree---2

Strongly disagree---1

\begin{tabular}{|c|c|c|c|c|c|c|}
\hline 1 & $\begin{array}{l}\text { I learn English because I want to meet and } \\
\text { converse with more and varied people in the } \\
\text { world. }\end{array}$ & 5 & 4 & 3 & 2 & 1 \\
\hline 2 & $\begin{array}{l}\text { I learn English because I want to better } \\
\text { understand the culture, society and people of } \\
\text { English-speaking countries. }\end{array}$ & 5 & 4 & 3 & 2 & 1 \\
\hline 3 & $\begin{array}{l}\text { I learn English because I want to behave in ways } \\
\text { similar to English-speaking people. }\end{array}$ & 5 & 4 & 3 & 2 & 1 \\
\hline 4 & $\begin{array}{l}\text { I want to enjoy foreign music, sports, or movies } \\
\text { by learning English. }\end{array}$ & 5 & 4 & 3 & 2 & 1 \\
\hline 5 & $\begin{array}{l}\text { I will be out of a circle of my friends if I do not } \\
\text { study English. }\end{array}$ & 5 & 4 & 3 & 2 & 1 \\
\hline
\end{tabular}

